\title{
DA CLASSIFICAÇÃO DE OBRAS LEXICOGRÁFICAS E SEUS PROBLEMAS: PROPOSTA DE UMA TAXONOMIA
}

\author{
Félix BUGUEÑO MIRANDA*
}

- RESUMO: Dentre os desafios pendentes da teoria metalexicográfica, um dos mais importantes é a geração de modelos de classificação de obras lexicográficas. Os modelos desenvolvidos até o presente momento obedecem a critérios impressionistas, funcionais ou linguísticos. $\mathrm{O}$ objetivo deste trabalho é apresentar um modelo de classificação de dicionários que integre dois critérios. Considerando que os dicionários são instrumentos linguísticos concebidos para um público-alvo determinado, uma proposta de classificação deveria levar em conta os critérios funcional e linguístico. No âmbito do critério funcional, estabelece-se uma distinção entre falantes nativos e falantes não nativos. No âmbito do critério linguístico, empregam-se parâmetros tais como o número de línguas, a oposição semasiologia/onomasiologia e uma concepção diassistêmica da linguagem. A proposta classificatória apresentada é do tipo taxonômico. Acredita-se que uma classificação taxonômica ofereça melhores resultados que uma proposta tipológica. É necessário salientar, no entanto, que ainda não é possível gerar uma classificação exaustiva de obras lexicográficas de validez universal.

- PALAVRAS-CHAVE: Metalexicografia. Classificação. Taxonomia.

\section{Introdução}

Em plena consonância com o exposto por Swanepoel (2003, p.44, tradução nossa), que afirma que "[...] construir tipologias ${ }^{1}$ de dicionários é um componente crucial da pesquisa lexicográfica."2, a classificação das obras de referência é importante tanto para o compilador (ou redator) do dicionário e seu usuário, como também para o avaliador. Para o compilador, uma classificação das obras lexicográficas permite desenhar um instrumento de consulta segundo um conjunto de padrões e parâmetros formais que garantam a sua real utilidade. Para o usuário, uma classificação de dicionários oferece um panorama das obras disponíveis, permitindo-lhe, assim, uma escolha mais acertada segundo as suas necessidades.

\footnotetext{
* UFRGS - Universidade Federal do Rio Grande do Sul. Instituto de Letras - Departamento de Línguas Modernas. Porto Alegre - RS - Brasil. 91540-000 - felixv@uol.com.br

1 O termo "tipologia", empregado por Swanepoel (2003, p.44), deve ser compreendido como equivalente de "classificação".

2 No original: [...] constructing dictionary typologies is a crucial component of dictionary research.
} 
Por último, para o crítico de dicionários, uma classificação constitui um subsídio que ajuda na tarefa avaliadora de obras lexicográficas.

\section{Tipos de classificação das obras lexicográficas}

É possível estabelecer três tipos de classificação de dicionários: impressionista, funcional e linguística.

Uma classificação impressionista ou fenomenológica ${ }^{3}$ corresponde àquela que distingue os dicionários por critérios externos à própria obra lexicográfica, tais como o tamanho ("minidicionário", "grande dicionário" , "dicionário de bolso" etc.). Essa classificação é empregada pelas próprias editoras. Assim, por exemplo, a editora alemã Langenscheidt oferece, no seu extenso catálogo editorial, uma classe de dicionários denominada Langenscheidt Universal Wörterbuch, que corresponde a dicionários bilíngues de tamanho reduzido, com uma densidade macroestrutural ${ }^{4}$ (segundo as suas próprias informações) de aproximadamente 25.000 lemas. A editora Bibliographisches Institut (mais conhecida pela sua série de dicionários Duden) possui, por outro lado, um dicionário monolíngue que intitula Duden Universal Wörterbuch, com uma densidade macroestrutural de 120.000 lemas (segundo as suas próprias informações). Em outras palavras, é evidente que Universal corresponde a uma expressão subjetiva.

Ainda no âmbito dos critérios impressionistas ou fenomenológicos, encontrase a classificação baseada na densidade macroestrutural. ${ }^{5}$ Embora, nesse caso, empregue-se um critério aparentemente interno à obra lexicográfica, ele não se sustenta como parâmetro universalmente válido de classificação. E há, pelo menos, três razões que o invalidam.

Em primeiro lugar, a variedade de obras lexicográficas que se obtém a partir de critérios numéricos estará sempre atrelada à tradição lexicográfica que serve para elaborar tal proposta. É o caso de Landau (2001), que ancora a sua classificação única e exclusivamente nos dicionários advindos da tradição editorial norte-americana. O US College dictionary, por exemplo, corresponde a um produto lexicográfico desenvolvido a partir das necessidades de um público bem delimitado, submetido a exigências acadêmicas específicas. No entanto, não há nada que permita estabelecer uma correlação entre o perfil desse público e a densidade macroestrutural da obra em questão, que oscila entre 160.000 e 180.000 lemas, e é o critério empregado para identificar essa classe de dicionários

\footnotetext{
3 A designação "fenomenológica" corresponde a Hausmann (1989, p.970).

4 "Densidade macroestrutural" é o número de lemas que um dicionário possui. Para esse conceito, confira Bugueño Miranda e Farias (2008, p.3).

5 Confira, por exemplo, Biderman (1998) e Landau (2001).
} 
em particular. Aliás, Landau (2001) reconhece que o produto dessa classificação só serve para caracterizar esse tipo específico de dicionários norte-americanos, e que na tradição lexicográfica britânica parece não haver uma correspondência parecida.

Em segundo lugar, não foram encontradas evidências, nos autores supracitados, que permitissem compreender como foi feito o cálculo da densidade macroestrutural, nem como se atrelou uma determinada densidade macroestrutural a uma determinada classe de dicionário.

Por fim, em terceiro lugar, e, talvez, o mais importante, ainda que se conseguisse estabelecer uma metodologia que permitisse tal correlação, a sua aplicabilidade ficaria restrita à relação entre determinada tradição lexicográfica e a língua que essa tradição espelha. Isto quer dizer que esses cálculos não podem ser transpostos a outras tradições lexicográficas. A língua alemã, por exemplo, constitui a conjugação de uma tradição lexicográfica amplamente desenvolvida (BUGUEÑO MIRANDA, 2008) com o fato de ter uma forte tendência à criação de compostos. ${ }^{6}$ Consequentemente, a quantidade de Komposita [compostos] lematizados nos dicionários dessa língua representa um impacto direto na densidade macroestrutural de qualquer dicionário. Em Bugueño Miranda (2004/2005, p.20) se compara, por exemplo, as 107 formas derivadas e compostas a partir do radical Wetter "tempo atmosférico" (e a sua variante não livre -witter-) com as 40 formas derivadas e compostas a partir da forma portuguesa alto em $\mathrm{Au}$ (1999, s.v.). Nessas condições, qualquer metodologia para calcular a densidade macroestrutural com o objetivo de classificar dicionários só poderia ser aplicável a tradições lexicográficas correspondentes a línguas que possuam características genéticas e tipológicas muito parecidas.

No que diz respeito a uma classificação funcional, ela está orientada pela função aferida ao dicionário. Nesse cenário, o modelo de Engelberg e Lemnitzer (2004) é o melhor expoente. No entanto, é pertinente salientar que, nessa proposta, a divisão dos dicionários pelo critério de "dicionários orientados por grupos de usuários" [Benutzergruppenorientiertes Wörterbuch] é só um critério de classificação entre outros. É necessário reconhecer também que, até o presente momento, os dicionários elencados a partir desse critério ficam restritos ao âmbito do ensino-aprendizagem, tanto de língua materna como de línguas estrangeiras. ${ }^{7}$

\footnotetext{
Em MLS (2000. s.v. Komposita), comenta-se, a esse respeito, que "no alemão, a composição no âmbito nominal é o tipo de formação léxica preferencial e ilimitadamente produtiva." [Im Dt. ist die Komposition im nominalen Bereich der bevorzugte Wortbildungstyp und uneingeschränkt produktiv].

7 Hausmann (1989, p.970) elenca, além do ensino-aprendizagem (decupado em aprendizagem sistemática / resolução de determinadas tarefas pontuais (por exemplo, palavras cruzadas)), as seguintes situações de uso: consulta / leitura aleatória (browsing), fins práticos / fins científicos, recepção textual / produção textual. Em nossa opinião, as situações de aprendizagem, consulta e fins específicos constituem fatos exógenos à linguagem, ao contrário da recepção / produção textual. Para fins deste trabalho, produção e recepção são consideradas variáveis linguísticas.
} 
A proposta de Engelberg e Lemnitzer (2004, p.21) distingue os seguintes dicionários: dicionário de aprendizes [Lernerwörterbuch], dicionário do léxico fundamental [Grundwortschatzwörterbuch], dicionário para as séries iniciais [Grundschulwörterbuch], ${ }^{8}$ dicionário escolar [Schulwörterbuch] e dicionário infantil [Kinderwörterbuch]. A proposta de Engelberg e Lemnitzer (2004) parece exequível, se se considera, por exemplo, que as diretrizes curriculares de um aprendiz (entre outras variáveis) permitem aferir uma função delimitada a essa série de dicionários, como pode ser comprovado, por exemplo, nos trabalhos de Farias (2009), Bugueño Miranda e Farias (2009) e Selistre (2012), além de Pires (2012), citado na nota 8. No entanto, e como ainda será discutido neste artigo, alguns dos membros dessa classificação, tais como o dicionário infantil, apresentam dificuldades no que diz respeito ao seu reconhecimento como uma classe específica de dicionários. Outro tanto acontece com os dicionários de aprendizes. A falta de critérios de imanência linguística impede, por exemplo, que a classificação de Engelberg e Lemnitzer (2004) permita a distinção entre a perspectiva semasiológica e a onomasiológica, questão fundamental em se tratando de dicionários de aprendizes, embora essa distinção seja aplicável também a outras classes de dicionários. Esse fato comprova, ademais, que uma classificação por critérios isolados, como a proposta por Engelberg e Lemnitzer (2004), é útil, mas necessariamente incompleta.

O terceiro tipo de classificação corresponde à classificação por critérios de imanência linguística, tais como o número de línguas, a perspectiva do ato da comunicação (BUGUEÑO MIRANDA, 2009) ou a concepção diassistêmica da linguagem (COSERIU, 1992). Nessa esteira, encontram-se as propostas de classificação de Haensch (1982) e Hausmann (1985). Embora tais classificações permitam "enquadrar" muitos dicionários, elas padecem do mesmo problema das propostas funcionais, isto é, a falta de complementariedade com outro parâmetro. Nesse caso concreto, falta o critério funcional.

\section{Problemas e desafios da classificação de obras lexicográficas}

Um enquadramento classificatório de dicionários está condicionado por duas variáveis. Em primeiro lugar, e do ponto de vista (meta)lexicográfico, os resultados do enquadramento dependem do modelo de classificação a ser empregado. Em segundo lugar, e do ponto de vista do produto lexicográfico, a constante aparição de novos dicionários, a heterogênea constituição de muitos deles, assim como a terminologia nem sempre clara com que muitas obras são intituladas também acabam influenciando os resultados.

Sobre as particularidades desses dicionários, o trabalho de Pires (2012) oferece uma sólida fundamentação teórica. 
No que diz respeito à fundamentação teórica para a classificação de obras lexicográficas, é possível distinguir dois "modelos". Esses modelos seguem a oposição entre taxonomia e tipologia. Uma taxonomia é uma classificação de acordo com um sistema de critérios pré-determinados, que almeja separar elementos de um grupo (taxon) em subgrupos (taxa), que são mutuamente excludentes e não ambíguos. Uma tipologia, por outro lado, corresponde a uma classificação que possibilita reunir uma densidade de entidades que compartilham algum traço mais evidente ou notório, que pode ser identificado como um protótipo (LÓPEZ ROLDÁN, 1996). Segundo Marradi (1990, p.133), uma taxonomia se baseia no princípio do "fundamentum divisionis", ou seja, um padrão de classificação que possibilita sucessivas operações "descendentes" para identificar entidades de acordo com a sua pertinência ao padrão classificatório escolhido. Uma classificação que opera com fundamenta divisionis sucessivos é chamada por Marradi (1990) de classificação intensional. Uma classificação extensional, é, por outro lado, uma classificação em que os fundamenta divisionis são considerados simultaneamente (MARRADI, 1990). Nesse caso, encontramo-nos diante de uma tipologia. Fazendo as transposições metodológicas necessárias, uma taxonomia lexicográfica corresponde a uma classificação por critérios dicotômicos descendentes. Uma tipologia lexicográfica, por outro lado, corresponde a uma classificação segundo um princípio centrípeto, na medida em que, na presença de vários traços, um deles sobressai e se converte no traço destacado de uma entidade, que apresenta também outros traços, mas com menos saliência. É necessário ressaltar, no entanto, que as designações "taxonomia" e "tipologia" são usadas, às vezes, de maneira indiferenciada (LÓPEZ ROLDÁN, 1996).

Segundo Kuhn (1989), no âmbito da metalexicografia, a classificação de dicionários por princípios taxonômicos ou tipológicos acarreta resultados diferentes, condicionada por dois fatores: a) a aparição constante de novas obras lexicográficas e b) o caráter heterogêneo que muitas obras lexicográficas apresentam. Isto tem um impacto direto no princípio classificador escolhido. Ao se optar por uma taxonomia, cada classe de dicionário que se consiga elencar no final da sucessão de fundamenta divisionis corresponde a uma matriz de traços (que equivale ao princípio das condições necessárias e suficientes). Cada obra lexicográfica que possa ser classificada por cumprir exaustivamente um check-list (matriz de traços) advindo da aplicação sucessiva de fundamenta classificacionis corresponde a um genótipo lexicográfico. ${ }^{9}$ Por outro lado, quando uma obra lexicográfica não consegue corresponder totalmente à matriz de traços que se deriva da sucessão de fundamenta comparationis (por apresentar só alguns traços, ou por ser difícil reconhecê-los), encontramo-nos em presença de um fenótipo

9 Para esse conceito, confira Bugueño Miranda (2008, p.89). 
lexicográfico. ${ }^{10}$ Dito em outros termos, um genótipo lexicográfico corresponde a uma linhagem de obras de referência que pode ser identificada claramente em função de uma determinada matriz de traços. Um fenótipo lexicográfico, por outro lado, corresponde a um dicionário que se caracteriza por não apresentar uma matriz de traços completa ou reconhecível. Ao se trabalhar com taxonomias, essa distinção é fundamental.

No âmbito da tipologia, a distinção entre genótipos e fenótipos se torna irrelevante, já que não se almeja reconhecer uma obra pelo princípio das condições necessárias e suficientes. Hausmann (1989, p.969) lembra que "[...] uma tipologia é uma classificação que se orienta por protótipos." ${ }^{11}$. Nessa concepção, um protótipo corresponde a um tipo de dicionário que representa o expoente mais típico e está no centro de uma categoria, em relação a outros que são menos típicos e que se encontram em uma posição mais periférica. O expoente lexicográfico apresenta um traço mais "saliente" ou "dominante". ${ }^{12}$ Além disso, uma classificação tipológica permite também acomodar melhor novos expoentes lexicográficos, assim como os que, neste trabalho, se denominam "fenótipos".

\section{As tentativas de classificação de obras lexicográficas}

Os esforços classificatórios estão relativamente presentes na discussão lexicográfica. É necessário avaliá-los, no entanto, em função das distinções feitas até aqui. Como já foi comentado, Biderman (1998) e Landau (2001) são dois expoentes de classificações fenomenológicas ou impressionistas. Kuhn (1989) e Engelberg e Lemnitzer (2004), por outro lado, representam esforços de classificação funcional. A proposta de Kuhn (1989) merece duas considerações. Embora o autor a intitule "Tipologia dos dicionários segundo opções de consulta" [Typologie der Wörterbücher nach Benutzungsmöglichkeiten], o princípio de ordenação corresponde claramente ao de uma taxonomia. Em segundo lugar, as funções aferidas pelo autor aparecem intrinsecamente unidas a um usuário específico. Assim, por exemplo, os dicionários destinados ao controle da competência linguística [Kompetenzkontrolle], dentre os quais se destaca o dicionário ortográfico, almejam satisfazer as necessidades de consulta de um aluno da educação básica e de uma secretária; os dicionários para traduzir, as de um aluno da educação básica, de um estudante universitário e de um tradutor. Trata-se de usuários preferenciais dessas classes de dicionários, mas não exclusivos. Dessa forma, um estudante universitário pode ser também um usuário

\footnotetext{
10 Para esse conceito, confira Bugueño Miranda e Farias (2011, p.50).

11 No original: "eine Typoplogie ist [... ] eine Klassifikation, die sich an Prototypen orientiert"

12 No expoente lexicográfico pode haver, portanto, traços menos dominantes ou, simplesmente, inexistentes.
} 
preferencial de um dicionário ortográfico, por exemplo. Se, por um lado, a função não pode ser decupada a partir do perfil de usuário, por outro lado é necessário reconhecer também que é só no âmbito do ensino-aprendizagem que, até agora, tem sido possível estabelecer (ainda que de modo parcial) um perfil de usuário mais preciso, posto que esse usuário está submetido a um conjunto de demandas que não são outras que as demandas curriculares, ${ }^{13}$ como já foi comentado em relação à proposta de Engelberg e Lemnitzer (2004). Em todos os demais casos, no que diz respeito ao usuário, atrelado a determinadas classes de dicionários, o modelo de Kuhn (1989) requer estudos complementares.

No que diz respeito às taxonomias linguísticas, os modelos de Haensch (1982), Hausmann (1985) e Martínez de Sousa (1995) se ordenam segundo esse princípio. Corresponde a Haensch (1982) o mérito de ter sido o primeiro a advertir que os modelos classificatórios gerados por critérios isolados oferecem representações muito parciais e imprecisas das obras lexicográficas. De fato, a proposta de Haensch (1982) é uma proposta de múltiplas entradas devido a esse fato. No entanto, Haensch (1982) não consegue integrar mais parâmetros ("critério linguístico" $X$ "função" $X$ "critério prático", por exemplo), de modo que o leitor se depara, às vezes, com uma mesma classe de dicionários em diferentes pontos de diferentes propostas classificatórias. O modelo de Martínez de Sousa (1995), por outro lado, corresponde a um modelo híbrido. Martínez de Sousa (1995), em um primeiro momento, elabora uma classificação por critérios estritamente linguísticos ("critério léxico", "critério sintagmático", "critério paradigmático", etc.). Essa classificação, no entanto, não é completamente convincente em relação aos expoentes lexicográficos que se obtêm por meio dela. Assim, por exemplo, sob o critério sintagmático aparece o dicionário sintático ou de sintaxe. No critério terminológico, por outro lado, aparece o expoente dicionário de valências verbais. É difícil entender por que Martínez de Sousa (1995) separa esses dois expoentes. Mais difícil ainda é entender o que é um "dicionário de sintaxe". ${ }^{14}$ Ciente das limitações que a aplicação de um único critério comporta, Martínez de Sousa (1995) gera também um segundo parâmetro, chamado de "Outras classificações". Sob esse critério, apresentam-se classes de dicionários tais como dicionário diacrônico, dicionário sincrônico, dicionário codificador, dicionário decodificador, etc. Curiosamente, é sob o parâmetro de classificação "Formas satélites" que se encontram alguns expoentes que correspondem ao que, neste trabalho, chama-se de critério funcional. Nessa rubrica, são mencionados, entre outros, o dicionário escolar e o dicionário infantil. No entanto, no final dessa listagem, aparece o dicionário pequeno [diccionario pequeño], que surge ainda uma segunda vez sob

${ }_{13}$ No caso específico dos dicionários de aprendizes, poder-se-ia acrescentar também os problemas de ordem contrastiva.

14 Como já foi comentado, a terminologia empregada para denominar muitos dicionários nem sempre contribui para obter clareza na tentativa de organizar um panorama das obras lexicográficas. 
o critério de Extensão e Formato [extensión y formato]. Assim, a classificação de Martínez de Sousa (1995) mistura critérios de imanência linguística com critérios extralinguísticos.

Em relação a essa taxonomia é pertinente, ainda, fazer outras duas observações. Em primeiro lugar, e como já foi comentado, uma classificação de dicionários espelha a tradição lexicográfica que tenta descrever e que não corresponde necessariamente aos resultados obtidos com a mesma classificação aplicada a outra tradição lexicográfica. Assim, por exemplo, Martínez de Sousa (1995) elenca, sob o critério léxico, o dicionário acadêmico [diccionario académico] e o dicionário de autoridades [diccionario de autoridades]. Em relação ao primeiro, essa classe de dicionários corresponde aos dicionários redigidos pelas entidades que se preocupam com a orientação idiomática, mais conhecidas como Academias da Língua, tais como a francesa, a italiana e a espanhola. No entanto, só a Real Academia Espanhola edita um dicionário que é tido como um instrumento de orientação no uso da língua. No caso das outras duas instituições, embora também editem ou tenham editado dicionários ${ }^{15}$ a tarefa de orientação fica por conta da iniciativa privada (PRob, 1993; VLI, 1992). Dessa forma, o dicionário acadêmico, isto é, um dicionário semasiológico que espelha a doutrina de orientação no uso da língua de uma Academia da Língua, e que é aceito consensualmente pela comunidade idiomática dessa língua, fica restrito à tradição lexicográfica hispânica. Uma situação análoga apresenta o dicionário de autoridades, que corresponde na verdade ao DAut (1726-1739), publicado pela Real Academia Espanhola com o intuito de respaldar os usos léxicos nas "autoridades literárias" desde fins do século XV até inícios do século XVIII. O modelo "dicionário de autoridades" nunca voltou a ser editado, mas simplesmente reimpresso, até que foram eliminadas da obra as abonações, surgindo assim, no século XIX, o que hoje se conhece como Diccionario de la Real Academia Española. Resulta questionável, portanto, que o dicionário de autoridades possa constituir uma classe de dicionário.

Por outro lado, e como também já comentado, as classes de dicionários que se derivam dos critérios empregados por Martínez de Sousa (1995) não conseguem tampouco ser completamente claras. Assim, por exemplo, se distingue entre "dicionário dialetal" e "dicionário de regionalismos", sem que se entenda bem a diferença entre eles.

Em geral, a classificação de Martínez de Sousa (1995) constitui uma tentativa, nem sempre bem sucedida, de catalogar dicionários. Os critérios de orientação linguística nem sempre conseguem oferecer um panorama claro, e a alternativa de se elencar mais classes sob a rubrica "Outras classificações" tampouco leva a um esclarecimento maior sobre as distintas classes de dicionários.

15 No caso do francês, o Dictionnaire de l'Académie Française (1992). 
No âmbito das tipologias, Hartmann e James (2001) propõem um exemplo de classificação orientada por protótipos. A tipologia de Hartmann e James (2001) está disposta em torno de dois círculos concêntricos, divididos por um eixo vertical e outro horizontal. O círculo exterior, no seu lado esquerdo, corresponde às obras de caráter geral [general]. No círculo interior, e no mesmo lado, o eixo horizontal serve para separar o critério de "informação linguística" [linguistic], no lado superior, do critério de "informação factual" [factual], no lado inferior. Assim, há obras de caráter geral e linguístico, sendo os seus expoentes prototípicos, dentre outros, o dicionário geral, o dicionário de aprendizes e o dicionário bilíngue. Há também obras gerais e factuais, sendo seus expoentes mais típicos a enciclopédia, o almanaque e o dicionário biográfico.

Do lado direito, o círculo externo corresponde ao critério das "obras especializadas" [specialized], cabendo ao círculo interno conter o critério "informação" [information]. No extremo superior, a interseção entre critério "especializado" e critério "informação" apresenta como expoentes mais prototípicos o dicionário de estrangeirismos, o dicionário de expressões idiomáticas e o dicionário de neologismos, entre outros. Já no lado inferior, a combinação entre critério especializado e critério de informação está reservada para os dicionários terminológicos, tais como o dicionário de geologia, o dicionário de química e o dicionário de música.

Em termos gerais, a proposta de Hartmann e James (2001) é coerente com o princípio de classificação por prototipicidade, sobretudo se se leva em conta o lado superior do círculo, tanto no âmbito das obras linguísticas (dicionário geral, dicionário de aprendizes etc.) como daquelas de cunho informativo (dicionário de estrangeirismos, dicionário de arcaísmos etc.). Estas últimas, de fato, poderiam ser consideradas como expoentes marginais em relação ao dicionário geral ou ao dicionário bilíngue. No entanto, não fica muito claro por que, no âmbito das obras linguísticas, aparece o dicionário dialetal, ao passo que o dicionário de gíria [dictionary of slang] foi classificado no âmbito das obras de informação. Da mesma forma, tampouco é possível entender completamente por que o guia de uso [usage guide] e o dicionário de parônimos, sinônimos e falsos amigos [dictionary of confusibles] aparecem em lugares diferentes da classificação, embora ambos constituam expoentes "menos prototípicos" em relação a muitas outras obras de consulta.

A proposta de Hartmann e James (2001) tampouco foge à tendência das classificações lexicográficas de incluir obras específicas pertinentes à tradição das obras de referência que espelham. A tipologia de Hartmann e James (2001), por exemplo, inclui o "companion", que corresponde a uma coleção de obras de referência de temática variada editada pela Oxford University Press. A série passou a constituir, assim, um protótipo de obras de consulta diferente, na própria tipologia de Hartmann e James (2001), da enciclopédia e do compêndio [compendium]. 
Em síntese, trata-se de uma concepção interessante de classificação de obras lexicográficas. É necessário salientar, no entanto, que essa abordagem deixa questões em aberto, tais como os traços prototípicos que permitem estabelecer a posição "mais central ou marginal" de determinadas obras lexicográficas.

\section{Proposta para uma classificação de obras lexicográficas ${ }^{16}$}

Considerando o exposto nos parágrafos anteriores, parece apropriado estabelecer uma axiomática ${ }^{17}$ básica no momento de elaborar uma tentativa de classificação de obras lexicográficas:

- Axioma 1: Uma classificação exaustiva e de aplicação universal é impossível, já que se detecta o surgimento constante de novas obras lexicográficas.

- Axioma 2: Uma opção classificatória taxonômica oferece vantagens em relação a uma opção classificatória tipológica, já que permite o estabelecimento de genótipos lexicográficos. Os genótipos, por sua vez, possibilitam uma melhor avaliação das diferentes obras lexicográficas.

- Axioma 3: Uma classificação taxonômica deve poder integrar o critério funcional e o critério linguístico.

\section{Fundamentação de uma classificação taxonômica}

O modelo taxonômico a ser proposto apresenta três restrições:

1. Embora assuma como critério a distinção entre dicionário monolíngue e dicionário bilíngue, esse último não será tratado nessa oportunidade. A razão para não tratar dos dicionários bilíngues é prática. Em Bugueño Miranda (2010), são estabelecidos parâmetros que permitem uma classificação de dicionários que descrevem duas línguas. Eles são: número de línguas, função, sentido da relação de equivalência e anissomorfismo. A sua inserção na Figura 1, por um problema de espaço, é inviável. A própria complexidade do tema aconselha, pois, um trabalho específico voltado à classificação de dicionários bilíngues.

2. Em relação aos dicionários de aprendizes, a classificação de Oliveira (2010) oferece um esquema abrangente e coerente desse genótipo lexicográfico. Assim como no caso dos dicionários bilíngues, razões de espaço tornam impossível a inserção da proposta de Oliveira (2010) na Figura 1.

16 Uma versão rudimentar do modelo de classificação proposto aqui, e baseado parcialmente em Swanepoel (2003), se encontra em Bugueño Miranda (2011, p.174).

17 Emprega-se uma axiomática básica com o objetivo de fundamentar cada uma das decisões que permitirão o desenho de uma classificação. Para o conceito de "axioma", confira Blackburn (1997, s.v. axioma). 
3. Os genótipos elencados não correspondem ao total de expoentes lexicográficos possíveis em uma dada tradição lexicográfica. Da mesma forma, podem não estar necessariamente realizados na mesma tradição.

Como exposto acima, a proposta taxonômica está ancorada em critérios funcionais e critérios linguísticos. Dos critérios funcionais: o critério a ser empregado é a distinção entre obras lexicográficas para falantes nativos de uma língua e obras lexicográficas para falantes não nativos de uma língua. Dos critérios linguísticos: os critérios linguísticos empregados são os seguintes:

1. Número de línguas consideradas: dicionário mono- ou bilíngue.

2. A distinção entre "discurso livre" (as unidades léxicas consideradas isoladamente) e "discurso repetido" (as unidades léxicas consideradas em um grau variável de amálgama entre elas).

3. A distinção entre ênfase informativa no plano do significante e ênfase informativa no plano do significado.

4. A distinção entre perspectiva semasiológica e perspectiva onomasiológica.

5. A distinção entre uma representação do léxico diassistemicamente inclusivo e uma representação do léxico diassistemicamente restritivo.

\section{Justificativa dos critérios a serem considerados em uma classificação taxonômica}

Dos critérios funcionais: a distinção entre dicionários para falantes nativos de uma língua e dicionários para falantes não nativos de uma língua se baseia em:

1. Competências linguísticas diferentes entre aqueles que possuem uma dada língua como $\mathrm{L}_{1}$ e aqueles que possuem uma dada língua como $\mathrm{L}_{2}$.

2. Tarefas a serem desenvolvidas por aqueles que possuem uma dada língua como $\mathrm{L}_{1}$ e aqueles que possuem uma dada língua como $\mathrm{L}_{2}$.

Dos critérios linguísticos: as distinções a serem empregadas se fundamentam em:

1. Número de línguas consideradas: Na opção "número de línguas", foi desconsiderada a opção "plurilíngue", em função de que o princípio do anissomorfismo linguístico ${ }^{18}$ torna inviável o tratamento lexicográfico de mais de duas línguas. ${ }^{19}$ Os chamados "dicionários plurilíngues" constituem, pois, um caso de fenótipo lexicográfico.

18 Para esse conceito, confira Bugueño Miranda (2010, p.66-67).

19 A única exceção de tratamento lexicográfico de mais de duas línguas é o caso do dicionário de internacionalismos. Nessa classe de dicionários, no entanto, não opera o princípio do anissomorfismo linguístico. 
2. Distinção entre "discurso livre" [freie Sprachtechnik] e "discurso repetido" [wiederholte Rede]: Essa distinção corresponde a Coseriu (1992), e é de fundamental importância, já que a oposição entre as expressões monolexemáticas e as expressões polilexemáticas, no que diz respeito à sua significação e/ou ao seu grau de coesão, corresponde a uma condição essencial da linguagem.

3. Distinção entre ênfase no significante e ênfase no significado: No âmbito do discurso livre, todo verbete encontra uma analogia com a concepção dicotômica do signo linguístico saussureano. ${ }^{20}$ Nessa esteira, os dicionários podem ser concebidos para oferecerem informações das unidades léxicas como significante ou como significado.

4. Distinção entre perspectiva semasiológica e perspectiva onomasiológica: A distinção entre a perspectiva semasiológica e a perspectiva onomasiológica se fundamenta na função de cada um dos participantes no circuito da comunicação. ${ }^{21}$ Como consequência desse modelo, a perspectiva semasiológica (ou de recepção da linguagem) assume, como premissa básica, a disposição do léxico visando o significado. Dessa forma, a macroestrutura de um dicionário de orientação semasiológica corresponde ao conjunto de significantes (representados pelos lemas) que possuem, cada um deles, uma predicação ou equação sêmica (BUGUEÑO MIRANDA, 2007a). Por outro lado, a perspectiva onomasiológica corresponde a uma ordenação macroestrutural que parte do significado (com as suas diferentes opções de estrutura de acesso) para obter os seus significantes ou designações (BUGUEÑO MIRANDA, 2007b).

5. Distinção entre concepção diassistêmica inclusiva e concepção diassistêmica restritiva: Segundo Coseriu (1992), toda língua histórica conforma um diassistema ou conjunto de línguas funcionais, representadas por eixos, conforme dimensões tais como espaço, tempo, modalidade expressiva, etc. A partir dessa distinção, os dicionários podem almejar a exaustividade, isto é, compilar o léxico de uma língua abarcando o maior número possível de eixos, ou considerando um único eixo (ver modelo em Figura 1).

\section{Considerações finais}

A taxonomia proposta demonstra que a classificação de obras lexicográficas é uma tarefa perfeitamente exequível. No entanto, a concepção do seu desenho deixa em evidência também as tarefas ainda pendentes nesse campo dos estudos lexicográficos.

20 Confira Lepschy (1969), para uma extensa discussão sobre as consequências, para a linguística, dessa concepção.

21 Confira Pelz (1975, p.44), para uma análise detalhada do modelo do Organon de K. Bühler. 
Em primeiro lugar, embora o chamado critério "impressionista ou fenomenológico" tenha sido deixado de lado, por ser considerado "não relevante" do ponto de vista teórico-metodológico, também é verdade que o usuário, para quem, em última instância, as obras lexicográficas são desenhadas, escolhe os dicionários justamente com base nesse critério. Isso significa afirmar que a metalexicografia ainda não consegue resolver um impasse, ou seja, que o olhar do leigo ainda não corresponde totalmente ao que a teoria lexicográfica tem a dizer e aportar sobre o objeto "dicionário". A famosa frase de H. E. Wiegand, sobre a existência, em algumas tradições lexicográficas, de um "cenário lexicográfico" [eine Wörterbuchlandschaft] cobra, assim, ainda mais importância, na medida em que para essas tradições a obra lexicográfica constitui um instrumento central de consulta. Nessas condições, o hiato entre o usuário e a teoria tenderá a diminuir e, consequentemente, os resultados da reflexão teórica, por um lado, e dos anseios do usuário, por outro, convergirão a pontos de maior consenso.

Em segundo lugar, uma taxonomia ainda não consegue representar de maneira completamente satisfatória as relações "multilaterais" que as obras lexicográficas guardam entre si. Assim, por exemplo, no âmbito da oposição discurso livre e discurso repetido, o dicionário fraseológico converteu-se em um expoente do discurso repetido. No entanto, essa classe de dicionários encontra uma justificativa de existência, porque esclarece a significação de estruturas pluriverbais, de modo que apresenta também o traço "com ênfase no significado". Eis aí a justificativa de haver propostas classificatórias prototípicas, já que elas oferecem uma melhor forma de "acomodar" essas relações, muito embora o critério prototípico tampouco esteja livre de problemas teórico-metodológicos.

Finalmente, os resultados demonstram que variáveis tais como a tradição lexicográfica que se almeje "espelhar" por meio de uma classificação, ou o surgimento de novas classes de dicionários, limitam também todo esforço de oferecer uma imagem estruturada das diferentes obras lexicográficas. 
1
0
0
0
0
1
01
0
0
0
0
0
02
0
0
0
0
0
0
0

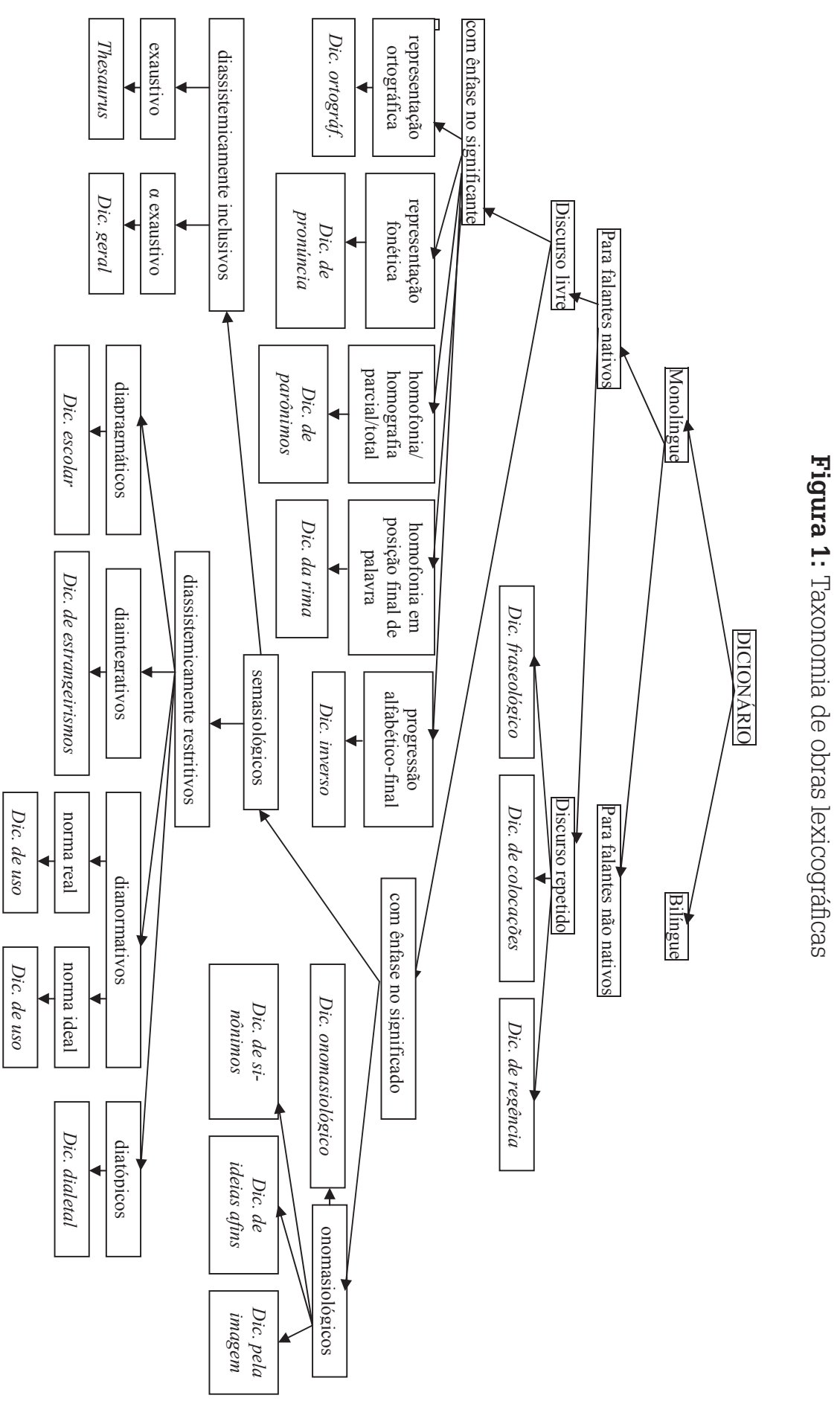


BUGUEÑO MIRANDA, F. On the classification of dictionaries and its challenges: a taxonomical proposal. Alfa, São Paulo, v.58, n.1, p.215-231, 2014.

- ABSTRACT:Among all the challenges of metalexicographic theory, one of the most important is the creation of classification models of lexicographic publications. Up to present time, the metalexicography has developed classification models according to phenomenological, functional and linguistic criteria. This paper aims at proposing a classification model that integrates two of these criteria. Taking in account the fact that a dictionary is a reference work about language, which is conceived for a specified target group, a lexicographic classification must be designed according to functional and linguistic criteria. Both criteria offer a wide range of parameters, for example: the distinction between a native speaker target group and a non-native speaker target group, the number of considered languages, the distinction between semasiology and onomasiology, a diasistemic approach to language, etc. This paper presents a taxonomical proposal since taxonomical classification seems to offer better results than a typological classification. It is necessary to emphasize that it is still not possible to design a comprehensive lexicographic classification that encloses all kind of dictionaries.

- KEYWORDS: Metalexicogrphy.Classification.Taxonomy.

\section{REFERÊNCIAS}

BIDERMAN, M. T. Os dicionários da contemporaneidade: arquitetura, métodos e técnicas. In: OLIVEIRA, A. M. P.; ISQUERDO, A. N. (Org.). As ciências do léxico: lexicologia, lexicografia, terminologia. Campo Grande: Ed. da UFMS, 1998. p.129142.

BLACKBURN, S. Dicionário Oxford de filosofia. Tradução de Desidério Murcho et al. Rio de Janeiro: Zahar, 1997.

BUGUEÑO MIRANDA, F. Panorama da lexicografia brasileira de orientação semasiológica. In: BATTISTI, E.; COLLISCHONN, G. (Org.). Língua e linguagem: perspectivas de investigação. Pelotas: EDUCAT, 2011. p.173-206.

O dicionário bilíngue como problema linguístico e lexicográfico. In: HWANG, Á. D.; NADIN, O. L. (Org.). Linguagens em interação III: estudos do léxico. Maringá: Clichetec, 2010. p.65-91.

Para uma taxonomia de paráfrases explanatórias. Alfa, São Paulo, v.53, n.1, p.243-260, 2009.

Panorama da lexicografia alemã. Contingentia, Porto Alegre, v.3, n.2, p.89-110, nov. 2008. Disponível em: <http://seer.ufrgs.br/contingentia/article/ view/6508/4241>. Acesso em: 19 set. 2012.

. O dicionário como reflexo da língua. Expressão, Santa Maria, n.1, p.97105, 2007a.

A definição do perfil de usuário e a função da obra lexicográfica em um dicionário de aprendizes. Expressão, Santa Maria, n.2, p.89-101, 2007b. 
. O que o professor deve saber sobre a nominata do dicionário de língua. Revista Língua \& literatura, Frederico Westphalen, n.10/11, p.17-31, 2004/2005. BUGUEÑO MIRANDA, F.; FARIAS, V. Princípios para o desenvolvimento de uma teoria da definição lexicográfica. Alfa, São Paulo, v.55, n.1, p.31-61, 2011.

. Panorama crítico dos dicionários escolares brasileiros. Lusorama, Frankfurt am Main, n.77/78, p.29-78, 2009.

O ensino de português e os dicionários escolares: um segmento informativo da microestrutura para fins de produção textual. Polifonia, Cuiabá, n.15, p.1-14, 2008.

COSERIU, E. Einfürung in die Allgemeine Sprachwissenschaft. Tübingen:Francke, 1992.

ENGELBERG, S.; LEMNITZER, L. Lexikographie und Wörterbuchbenutzung. Tübingen: Stauffenburg, 2004.

FARIAS, V. Desenho de um dicionário escolar de língua portuguesa. 2009. $286 \mathrm{f}$. Dissertação (Mestrado em Letras) - Instituto de Letras, Universidade Federal do Rio Grande do Sul, Porto Alegre, 2009.

HAENSCH, G. La Lexicografia: de la lexicografía teórica a la lexicografía práctica. Madrid: Gredos, 1982.

HARTMANN, R. R. K; JAMES, G. Dictionary of Lexicography. London: Routledge, 2001.

HAUSMANN, F. J. Wörterbuchtypologie. In: HAUSMANN, F. J. et al. (Hrsgn.). Wörterbücher, dictionaries, dictionnaires: ein internationales Handbuch zur Lexikographie. Berlin:Walter de Gruyter, 1989. p.968-988.

. Lexikographie. In: SCHWARZE, Ch.;WUNDERLICH, D. (Hrsgn.). Handbuch der Lexikologie. Königstein/Ts.: Athenäum, 1985. p.367-411.

KUHN, P. Typologie der Wörterbücher nach Benutzungsmöglichkeiten. In: HAUSMANN, F. J. et al. (Hrsgn.). Wörterbücher, dictionaries, dictionnaires: ein internationales Handbuch zur Lexikographie. Berlin: de Gruyter, 1989. p.111-127.

LANDAU, S. Dictionaries: the art and craft of Lexicography. Cambridge: CUP, 2001.

LEPSCHY, G. Die strukturale Sprachwissenschaft. München: Nymphenburger, 1969.

LÓPEZ ROLDÁN, P. La construcción de tipologías: metodología de análisis. Papers: revista de sociologia, Barcelona, n.48, p.9-29, 1996. Disponível em: <http://ddd. uab.cat/pub/papers/02102862n48/02102862n48p9.pdf>. Acesso em: 22 set. 2012.

MARRADI, A. Classification, typology, taxonomy. Quality and Quantity: international journal of methodology, Berlin, v.24, n.2, p.129-157, 1990. Disponível 
em: <http://www.me-teor.it/marr_opere/english/Classfqqq.pdf>. Acesso em: 22 set. 2012.

MARTÍNEZ DE SOUSA, J. Diccionario de lexicografía práctica. Barcelona: Bibliograf, 1995.

OLIVEIRA, A. F. Taxonomia de dicionários monolíngues de inglês para falantes não nativos. Signo, Santa Cruz, n.36, p.224-241, 2010. Disponível em: <http:// online.unisc.br/seer/index.php/signo/article/viewFile/1429/1307>. Acesso em: 22 set. 2012.

PELZ, H. Linguistik für Anfänger. Hamburg: Hoffmann und Campe, 1975.

PIRES, I. Desenho da macroestrutura de um dicionário escolar para as séries iniciais. 2012. 240f. Dissertação (Mestrado em Letras) - Instituto de Letras, Universidade Federal do Rio Grande do Sul, Porto Alegre, 2012.

SELISTRE, I. C. Desenho de um dicionário passivo inglês / português para estudantes de ensino médio. 2012. 301f. Tese (Doutorado em Linguística) Instituto de Letras, Universidade Federal do Rio Grande do Sul, Porto Alegre, 2012.

SWANEPOEL, P. Dictionary typologies: a pragmatic approach. In: STERCKENBURG, P. (Ed.). A practical guide to Lexicography. Amsterdam: John Benjamin, 2003. p.44-69.

\section{REFERÊNCIAS LEXICOGRÁFICAS}

[Au]. FERREIRA, A. B. de H. Novo Aurélio século XXI: o dicionário da língua portuguesa. 3.ed. Rio de Janeiro: Nova Fronteira, 1999.

[DAut]. REAL ACADEMIA ESPAÑOLA. Diccionario de Autoridades. Ed. facsimilar. Madrid: RAE, 1726-1739.

[MLS]. GLÜCK, H. (Hrsg.). Metzler Lexikon Sprache. 2. auflage. Stuttgart: Metzler, 2000.

[PRob]. Nouveau Petit Robert. Paris: Le Robert, 1993.

[VLI]. Vocabolario della lingua italiana. 11.ed. Bologna: Zanicelli, 1992.

Recebido em outubro de 2012.

Aprovado em janeiro de 2013. 
